\title{
Squamous cell carcinoma of the lung: clinical criteria for treatment strategy
}

Agnese Savini, Rossana Berardi, Paola Mazzanti, Miriam Caramanti, Matteo Santoni, Mariagrazia De Lisa, Francesca Morgese, Silvia Rinaldi, Mariangela Torniai, Ilaria Fiordoliva, Azzurra Onofri, Stefano Cascinu

Medical Oncology Unit, Università Politecnica delle Marche, Azienda Ospedaliero-Universitaria Ospedali Riuniti, 60126 Ancona, Italy.

Correspondence to: Dr. Rossana Berardi, Medical Oncology Unit, Università Politecnica delle Marche, Azienda Ospedaliero-Universitaria Ospedali Riuniti, Umberto I, GM Lancisi, G Salesi di Ancona Via Conca 71, 60126 Ancona, Italy. E-mail: r.berardi@univpm.it

\section{A B S T R A C T}

Aim: Primary lung cancer is the leading cause of human cancer deaths worldwide, and squamous cell carcinoma (SCC) is one of the most frequent histologic subtypes. The aim of our study was to analyze clinical factors potentially affecting the overall outcome of advanced lung SCC patients. Methods: A series of 72 consecutive patients with advanced SCC undergoing chemotherapy at our institution between January 2007 and July 2013 were eligible for our analysis. Results: By univariate analysis, a better overall survival (OS) was related to response to first-line chemotherapy: median OS were $19.7 v s$. 7.17 months, respectively, for responders and nonresponders patients $(P<0.0001)$. Eastern Cooperative Oncology Group performance status, gender, and surgery were other prognostic factors. No significant relationship between OS and smoking status, age, body mass index, or type of treatment was found. In the third-line setting, a better OS was associated with objective response to second-line treatment $(P=0.015)$. Conclusion: Our results suggest that differences in OS seem strictly associated with clinical response to previous treatments. These data should be considered in the therapeutic strategy and management of patients with SCC of the lung.

Key words: Non-small cell lung cancer, prognostic factors, squamous cell carcinoma

\section{Introduction}

Squamous cell carcinoma (SCC) represents $25-30 \%$ of all non-small cell lung cancer (NSCLC). ${ }^{[1]}$ It is due to the transformation of bronchial epithelium caused primarily by cigarette smoking and shows a remarkable dose-dependence with it. Typically, SCC originates in bronchial airways, in particular, those proximal and of medium caliber while adenocarcinoma (ADC) occurs in about $50 \%$ of cases and is localized to bronchi of smaller diameter. $\mathrm{ADC}$ is the most frequent histological type in nonsmokers, and its pathogenesis differs from SCC.

In general, SCC tends to be locally aggressive with metastasis to distant organs occurring less frequently than in ADC. New treatment options for ADC underline the need for mandatory subtyping. ${ }^{[2]}$ In particular, mutations in the epidermal growth factor receptor (EGFR) kinase, as well as fusions involving anaplastic lymphoma kinase (ALK), have led to a remarkable improvement in personalized therapy for ADC..$^{[3,4]}$ Unfortunately, activating mutations in EGFR and ALK fusions are

\begin{tabular}{|l|l|}
\hline \multicolumn{2}{|c|}{ Access this article online } \\
\hline Quick Response Code: & Website: \\
\hline & www.jcmtjournal.com \\
\cline { 2 - 2 } & \\
\hline
\end{tabular}

typically absent in $\mathrm{SCC}^{[5]}$ and targeted agents developed for ADC are largely ineffective against SCC. The aim of our study was to analyze clinical factors potentially affecting the outcome of advanced SCC in clinical practice. This was done to identify criteria that can help physicians to select the best treatment strategy in their clinical settings.

\section{Methods}

The study includes patients with locally advanced or metastatic (tumor-node-metastasis (TNM) stage III-IV) SCC of the lung undergoing chemotherapy at our institution between January 2007 and July 2013. Age, smoking history, sex, Eastern Cooperative Oncology Group (ECOG) performance status (PS), body mass index (BMI), and pathological stage of disease (TNM) were included in recorded patient characteristics and clinical features. The following data were collected for each patient: first and second-line chemotherapy details and surgical resection or radiotherapy information if performed. Tumor response was evaluated according to the Response Evaluation Criteria in Solid Tumors (RECIST 1.1).

The statistical association between categorical variables and clinical outcome was assessed with a Chi-square test. We used Kaplan-Meier analysis to measure survival distribution. Tested variables included sex (male vs. female), age $(>65 v s . \leq 65)$, ECOG PS $(0 v s . \geq 1)$, BMI $(<25 v s$. 25-29.9 vs. $\geq 30$ ), smoking status (never smoker vs. smoker/ former smoker), stage (III vs. IV), surgery (surgery vs. not 
surgery), radiotherapy (radiotherapy vs. not radiotherapy), type of chemotherapy (two-drug chemotherapy regimens including platinum and gemcitabine $v s$. gemcitabine alone $v s$. docetaxel vs. others), response to first and second-line chemotherapy (responders vs. nonresponders). Cox multiple regression analysis was used to assess the role of those variables resulting in significance by univariate analysis. Overall survival (OS) was defined as interval between start of chemotherapy to death or last follow-up visit. Progression-free survival (PFS) was defined as interval between start of treatment to clinical progression or death or last follow-up visit if not having disease progression. Significant differences in probability of surviving between strata were evaluated by log-rank test. A significance level of 0.05 was chosen to assess statistical significance. Statistical analyses were performed using MedCalc version v9.4.2.0 (MedCalc Software, Broekstraat 52, 9030 Mariakerke, Belgium).

\section{Results}

Between January 2007 and July 2013, 72 patients undergoing chemotherapy for advanced SCC of the lung at our institution were included in the analysis. Median age at diagnosis was 68 years (range: $45-83$ ); male/female ratio was $60 / 12$. The majority of patients $(56 \%)$ presented with stage IV, while 32 patients had stage IIIA (29\%) and IIIB (15\%) stage. Twenty-three patients (32\%) underwent surgery, and 12 of these had adjuvant therapy. Table 1 summarizes patient characteristics. Median OS in all patients was 12.3 months (range: 1.1-72.5). By univariate analysis, gender $(P=0.026)$, PS $(P=0.0009)$ and surgery $(P=0.02)$ were related to OS. No significant relationship was found between OS and age, type of treatment, smoking status, or BMI.

In the first-line setting, we observed partial responses (PR) in 21 patients $(29 \%)$, progressive disease (PD) in 30 cases $(42 \%)$, with 10 patients (14\%) showing stable disease (SD). No complete remissions (CR) were obtained. In 11 cases (15\%) response was not reported.

By univariate analysis, a better OS $(P<0.0001)$ and a better PFS $(P<0.0001)$ were associated with response to first-line chemotherapy: median OS was $19.7 v s$. 7.17 months for responders and nonresponders patients, respectively [Figure 1]. Median PFS was 8.5 months in responders as compared to 2.9 months in nonresponders [Figure 2].

These variables, with the exception of PS, maintained statistical significance even by multivariate analysis and proved to independently affect the outcome: sex $(P=0.019)$, surgery $(P=0.036)$, response to first-line therapy $(P<0.0001)$. Thirty patients $(42 \%)$ received chemotherapy as second-line therapy. Median OS in this group was 6.43 months (range: 0.6-54.4), with PFS of 3.1 months (range: 0.4-51.4). Moreover, in the second-line setting, better OS was associated
Table 1: Patients and tumor characteristics

\begin{tabular}{lc}
\hline Characteristics & $\boldsymbol{n}(\mathbf{\%})$ \\
\hline Patients (median age 68 years old, range: $45-83)$ & 72 \\
Stage & \\
III A & $21(29)$ \\
III B & $11(15)$ \\
IV & $40(56)$ \\
Sex & \\
Male & $60(83)$ \\
Female & $12(17)$ \\
Smoking status & \\
Ever smoker & $66(92)$ \\
Never smoker & $6(8)$ \\
Performance status & \\
0 & $44(61)$ \\
1 & $26(36)$ \\
$\geq 2$ & $2(3)$ \\
Surgery & \\
Yes & $23(32)$ \\
No & $49(68)$ \\
Radiotherapy & \\
Yes & $24(33)$ \\
No & $48(67)$ \\
Chemotherapy & \\
Platinum + gemcitabine & \\
Gemcitabine & \\
Docetaxel & $15(67)$ \\
Other & $2(3)$ \\
\hline
\end{tabular}

with response to previous chemotherapy $(P=0.015)$ : median OS 18.77 and 5.83 months for responders and nonresponders, respectively [Figure 3]. A significant impact in terms of different PFS was seen as a function of response to second-line therapy (5.9 vs. 2.7 months, $P=0.007)$. Finally, only 11 patients received third-line chemotherapy.

\section{Discussion}

Genomic alterations in SCC of the lung have not been comprehensively characterized, and molecular targeted therapies have mainly shown no efficacy. To date, the most important molecular and therapeutic achievements in advanced NSCLC have been mostly confined to patients with nonsquamous histology. However, recent research is focusing on identifying potential driver mutations affecting SCC patients. ${ }^{[6,7]}$ In a recent large phase III trial, necitumumab added to cisplatin and gemcitabine as first-line treatment increased survival in patients with advanced SCC. ${ }^{[8,9]}$ Nevertheless, at present, the standard frontline treatment remains exclusively chemotherapy. For patients with locally advanced or metastatic SCC, two-drug chemotherapy regimens (including cisplatin or carboplatin and a third-generation agent, such as gemcitabine, taxanes, or vinorelbine) currently remain the standard of treatment options. ${ }^{[10]}$ A single agent (mainly docetaxel) is the preferred treatment in second-line setting. ${ }^{[1]}$ 


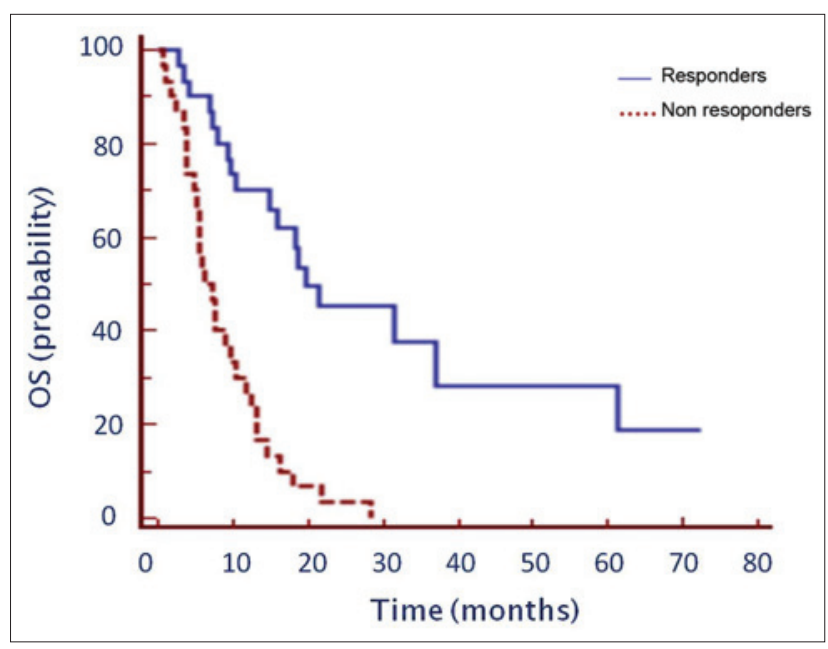

Figure 1: Median overall survival of patients as function of response to first-line chemotherapy, $P<0.0001$

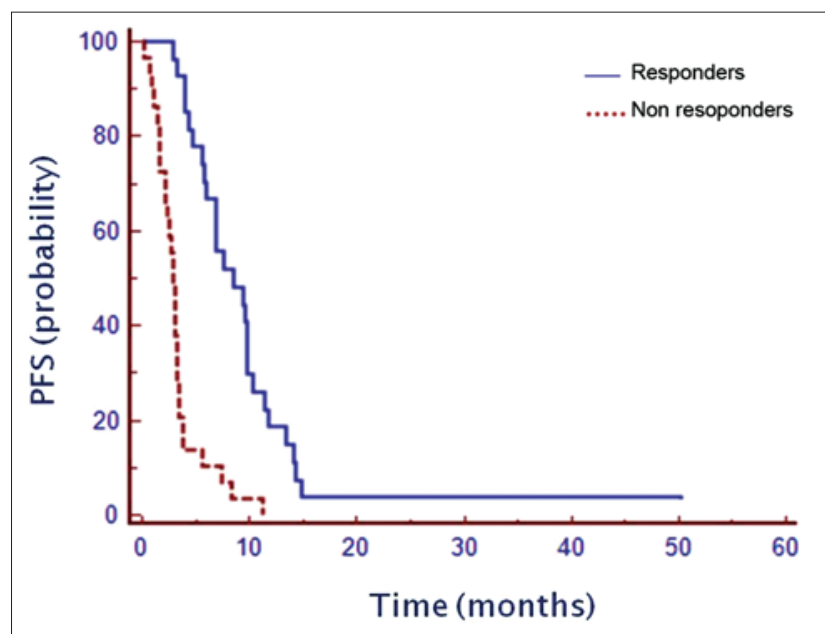

Figure 2: Median-progression free survival of patients as function of response to first-line chemotherapy, $P<0.0001$

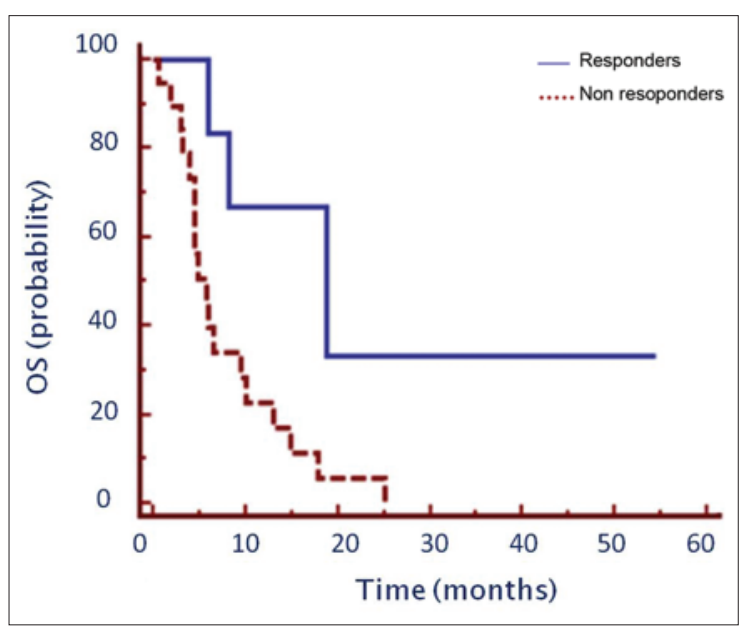

Figure 3: Median overall survival of patients as function of response to second-line chemotherapy, $P=0.015$

In our study, we analyzed clinical factors potentially influencing the overall outcome of patients with advanced lung SCC to identify a population of patients likely to benefit from chemotherapy with a prolonged life expectancy. Previous publications have suggested various prognostic factors involved in advanced NSCLC using heterogeneous patient populations. ${ }^{[12-15]}$ In a recent study, 245 patients were analyzed with the aim of evaluating factors associated with long-term survival ( $>2$ years) in patients with advanced NSCLC. Fifty-two patients (21\%) had SCC. Six prognostic factors were identified: PS of 0-1 at first tumor progression, normal lactate dehydrogenase levels at diagnosis, use of maintenance therapy, surgical resection, time to progression of $>3$ months, and number of chemotherapy agents received. ${ }^{[13]}$ Conversely, our study showed that a better PS at diagnosis was significantly associated with a better OS. In another large report, FLEX ${ }^{[15]}$ investigated the prognostic significance of baseline characteristics and showed that age, gender, PS, smoking status, tumor histology, and number of involved organs were independent factors of prognostic value. Interestingly, in our analysis, those factors did not show an impact on outcome while response to first-line chemotherapy was the major determinant for OS. A previous retrospective study evaluated the impact of first-line chemotherapy on results of second-line chemotherapy, using data from a large phase III study. One hundred and seventy-one (30\%) of 571 patients had SCC. The study showed that gender, histology, stage at diagnosis, PS at the beginning of second-line therapy, and best response to initial therapy were associated with survival outcome. In particular, median survival was 15.8 months in cases of CR/PR, 10.5 months in cases of $\mathrm{SD}$ and 4.6 months for PD $(P<0.001){ }^{[16]}$

In advanced colorectal cancer, it has been shown that patients eventually receiving all available drugs have a better OS. ${ }^{[17]}$ Similarly, in our study, patients responding to first-line chemotherapy had better OS and for those patients, receiving second-line therapy to maximize OS seemed important. Overall, despite heterogeneous treatment characteristics, our findings seem to indicate that SCC patients who responded to therapy may most benefit from additional treatments and this result could be relevant for the decision making process and the therapeutic strategy.

In conclusion, response to first-line and second-line treatments seems to have a significant prognostic impact in SCC. These observations should be considered relevant for the management of such patients, although further studies also based on biological markers are essential to better understand the prognostic factors in this population.

\section{References}

1. Travis WD. Pathology of lung cancer. Clin Chest Med 2011;32:669-92.

2. Thunnissen E, Kerr KM, Herth FJ, Lantuejoul S, Papotti M, Rintoul RC, Rossi G, Skov BG, Weynand B, Bubendorf L, Katrien G, Johansson L, López-Ríos F, Ninane V, Olszewski W, Popper H, Jaume S, Schnabel P, Thiberville L, 
Laenger F. The challenge of NSCLC diagnosis and predictive analysis on small samples. Practical approach of a working group. Lung Cancer 2012;76:1-18.

3. Giaccone G. Epidermal growth factor receptor inhibitors in the treatment of non-small-cell lung cancer. J Clin Oncol 2005;23:3235-42.

4. Kwak EL, Bang YJ, Camidge DR, Shaw AT, Solomon B, Maki RG, Ou SH, Dezube BJ, Jänne PA, Costa DB, Varella-Garcia M, Kim WH, Lynch TJ, Fidias P, Stubbs H, Engelman JA, Sequist LV, Tan W, Gandhi L, Mino-Kenudson M, Wei GC, Shreeve SM, Ratain MJ, Settleman J, Christensen JG, Haber DA, Wilner K, Salgia R, Shapiro GI, Clark JW, Iafrate AJ. Anaplastic lymphoma kinase inhibition in non-small-cell lung cancer. $N$ Engl $J$ Med 2010;363:1693-703.

5. Rekhtman N, Paik PK, Arcila ME, Tafe LJ, Oxnard GR, Moreira AL, Travis WD, Zakowski MF, Kris MG, Ladanyi M. Clarifying the spectrum of driver oncogene mutations in biomarker-verified squamous carcinoma of lung: lack of EGFR/KRAS and presence of PIK3CA/AKT1 mutations. Clin Cancer Res 2012;18:1167-76.

6. Metro G, Crinò L. Novel molecular trends in the management of advanced non-small-cell lung cancer. Expert Rev Anticancer Ther 2012;12:729-32.

7. Riess JW, Wakelee HA. Metastatic non-small cell lung cancer management: novel targets and recent clinical advances. Clin Adv Hematol Oncol 2012;10:226-34.

8. Thatcher N, Hirsch FR, Szczesna A, Ciuleanu TE, Szafranski W, Dediu M, Ramlau R, Galiulin R, Bálint B, Losonczy G, Kazarnowicz A, Park K, Schumann C, Reck M, Paz-Ares L, Depenbrock H, Nanda S, Kruljac-Letunic A, Socinski MA. A randomized, multicenter, open-label, phase III study of gemcitabine-cisplatin (GC) chemotherapy plus necitumumab (IMC-11F8/LY3012211) versus GC alone in the first-line treatment of patients (pts) with stage IV squamous non-small cell lung cancer (sq-NSCLC). J Clin Oncol 2014;32:5s.

9. Pirker R. Epidermal growth factor receptor-directed monoclonal antibodies in nonsmall cell lung cancer: an update. Curr Opin Oncol 2015;27:87-93.

10. Peters S, Adjei AA, Gridelli C, Reck M, Kerr K, Felip E; ESMO Guidelines Working Group. Metastatic non-small-cell lung cancer (NSCLC): ESMO clinical practice guidelines for diagnosis, treatment and follow-up. Ann Oncol 2012;23:vii56-64.

11. Scagliotti GV, Novello S, Rapetti S, Papotti M. Current state-of-the-art therapy for advanced squamous cell lung cancer. Am Soc Clin Oncol Educ Book 2013;2013:354-8.

12. Aggarwal C, Langer CJ. Older age, poor performance status and major comorbidities: how to treat high-risk patients with advanced non small cell lung cancer. Curr Opin Oncol 2012;24:130-6.

13. Giroux Leprieur E, Lavole A, Ruppert AM, Gounant V, Wislez M, Cadranel J, Milleron B. Factors associated with long-term survival of patients with advanced non-small cell lung cancer. Respirology 2012;17:134-42.

14. Leung EY, Scott HR, McMillan DC. Clinical utility of the pretreatment Glasgow prognostic score in patients with advanced inoperable non-small cell lung cancer. $J$ Thorac Oncol 2012;7:655-62.

15. Pirker R, Pereira JR, Szczesna A, von Pawel J, Krzakowski M, Ramlau R, Vynnychenko I, Park K, Eberhardt WE, de Marinis F, Heeger S, Goddemeier T, O'Byrne KJ, Gatzemeier U. Prognostic factors in patients with advanced non-small cell lung cancer: data from the phase III FLEX study. Lung Cancer 2012;77:376-82.

16. Weiss GJ, Rosell R, Fossella F, Perry M, Stahel R, Barata F, Nguyen B, Paul S, McAndrews P, Hanna N, Kelly K, Bunn PA Jr. The impact of induction chemotherapy on the outcome of second-line therapy with pemetrexed or docetaxel in patients with advanced non-small-cell lung cancer. Ann Oncol 2007;18:453-60.

17. Grothey A, Sargent D, Goldberg RM, Schmoll HJ. Survival of patients with advanced colorectal cancer improves with the availability of fluorouracil-leucovorin, irinotecan, and oxaliplatin in the course of treatment. $J$ Clin Oncol 2004;22:1209-14.

How to cite this article: Savini $A$, Berardi $R$, Mazzanti $P$, Caramanti M, Santoni M, De Lisa M, Morgese F, Rinaldi S, Torniai M, Fiordoliva I, Onofri A, Cascinu S. Squamous cell carcinoma of the lung: clinical criteria for treatment strategy. J Cancer Metastasis Treat 2015;1:90-3.

Received: 01-03-2015; Accepted: 13-05-2015.

Source of Support: Nil, Conflict of Interest: None declared. 